\title{
Anomalous changes of vertical geomagnetic field in Kamchatka
}

\author{
Yuriy Moroz ${ }^{1, \star}$, Sergey Smirnov ${ }^{2}$, and Zoya Nazarova ${ }^{3}$ \\ ${ }^{1}$ Institute of Volcanology and seismology, Far Eastern Branch, Russian Academy of Sciences \\ ${ }^{2}$ Institute of Cosmophysical Research and Radio Wave Propagation of the Far Eastern Branch of Russian \\ Academy of Science \\ ${ }^{3}$ Kamchatka Branch of the Geophysical Service of the Russian Academy of Sciences
}

\begin{abstract}
Secular variations of the vertical geomagnetic field at Paratunka (Kamchatka), Kakioka (Honshu), Mamambetsu (Hokkaido) and Patrony (Irkutsk) are considered from 1968 to 2014. Comparative analysis of secular variations showed that from 1968 to 2001, similar variations with the intensity of first hundreds on $\mathrm{nT}$ are obvious at four observatories. For the following period from 2001 to 2014, the secular variation at Paratunka observatory differs from other observatories. This disagreement of the secular geomagnetic variation at Paratunka observatory is timed to the increase of seismicity at the depth of 400-700 km in South Kamchatka region. It is suggested that in the result of increase of the seismicity in the region of transition from the upper to lower mantle, physical and chemical processes became more active. That caused formation of a large geo-electrical inhomogeneity which affected the behavior of the vertical component of geomagnetic field.
\end{abstract}

Investigation of secular variations of the geomagnetic field measured at the observatories in the north-western part of the Pacific ocean, allow us to draw conclusions on the features of geodynamic processes of this region. To do that, we chose the data of geomagnetic field secular variations at the observatories located on mainland (Irkutsk), on Honshu (Kakioka) and Hokkaido (Mamambetsu) islands and on Kamchatka (Paratunka) peninsula (Fig. 1).

There are continuous long-term observations of the geomagnetic field at these observatories (http://intermagnet.org/imos). Synchronous intervals of observations from 1968 to 2014 were selected in the time series. The analysis was carried out for three components of the geomagnetic field $(\mathrm{H}, \mathrm{D}$, $\mathrm{Z}$ ). The main attention was given to $\mathrm{Z}$ component which is more sensitive to geo-electric inhomogeneities of a medium. Comparative analysis of vertical component secular variations at Paratunka, Kakioka, Mamambetsu and Irkutsk indicates the following. Similar variations are obvious at four observatories for the period from 1968 to 2001 (Fig. 2). Variation intensity is the first hundreds of nT. We should note that from 2001 to 2014, variations with the intensity of about $100 \mathrm{nT}$ were observed in the annual variations only at Irkutsk, Kakioka and Mamambetsu observatories. This variation is not almost obvious at Paratunka observatory. The question arises, why the secular variation at Paratunka observatory differs from the annual variations of Patrony, Kakioka and Mamambetsu observatories for the latest 14 years.

We refer to the possible nature of secular variations. There are secular variations in the behavior of the magnetic field. They are associated with the change of external ionospheric, magnetospheric,

^e-mail: morozyf@kscnet.ru 


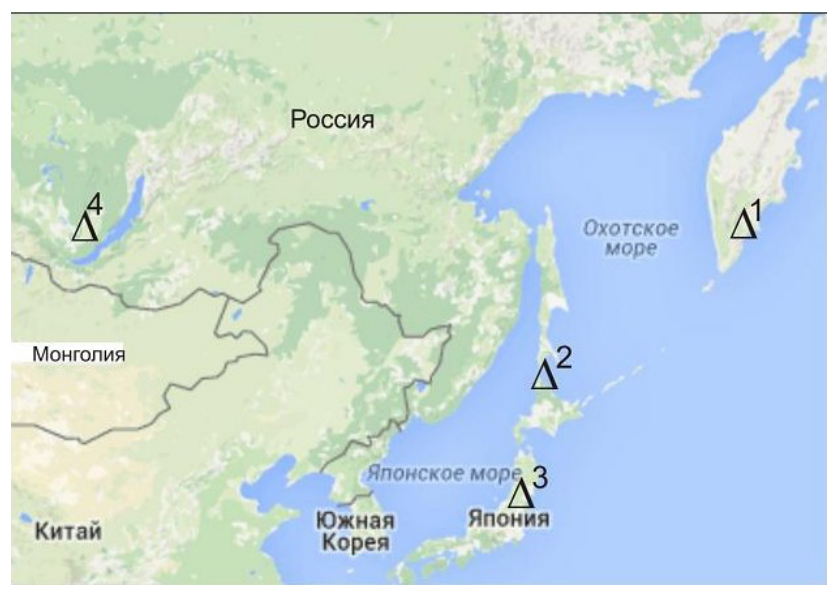

Figure 1. Scheme of location of geomagnetic observatories. 1-Paratunka; 2-Mamambetsu; 3-Kakioka; 4-Patrony (Irkutsk)

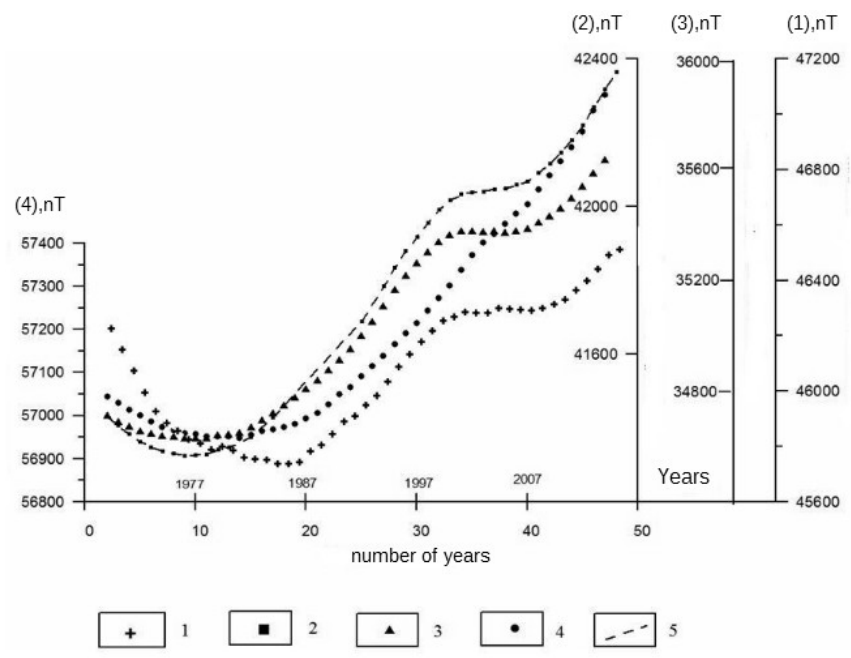

Figure 2. Secular variations of the geomagnetic field vertical component intensity at Paratuka (1), Mamambetsu (2), Kakioka (3), Patrony (4) observatories. 5- absence of values of field intensity at Mamambetsu observatoriy

crust and magnetohydrodynamic sources located in the core liquid part [6,10]. Changes of the field from crust sources are not large. They are of the first $\mathrm{nT}$ and are mainly observed in seismically active regions. Secular variations from the external sources are estimated to be of the first tens of nT. Their intensity is much less than the variations of magnetohydrodynamic sources. It was suggested before that variations with the periods of 11 years and less may exist in depth sources but due to the screening effect of the upper well-conductive mantle do not penetrate to the Earth's surface. Variations with such periods are associated only with external sources. Mechanisms of magnetohydrodynamic generation of field also did not concede generation of variations with the periods less than 10000-100000 years. 
However, based on the paper by Karry [11], Braginskiy [3] proved that variations with the periods from 4 to 33 years may be associated with the turbulence pulsations in the core liquid part. According to [11], such variations of nondipole field may be of regional character and occur not over the whole surface of the Earth.

Thus, we may suggest that variations with the intensity of the first hundreds of $\mathrm{nT}$ in the secular variations of Paratunka, Patrony, Kakioka and Mamambetsy observatories are regional. As it was mentioned before, the variations are similar during the period from 1968 to 2001 and during the following period the variation almost did not repeat at Paratunka observatory.

We assume that the discovered features may be determined by the change of mantle physical state. Information of the dynamics of rock physical properties at large depths $(400-700 \mathrm{~km})$ is obtained from the data of long-term seismic monitoring on www.globalcmt.org/CMT search $/ \mathrm{html}$ (global) and data.emsd.iks.ru/dbquaketxt_min (regional) networks of seismological stations. Seismicity is considered at the distances comparable with the distances to the hypocenters of strong deep earthquakes which could have significant impact on the physical state of the upper mantle. The analysis showed that there were no strong earthquakes $(M \geq 6)$ at the indicated depths within the latest 35 years in Japan and the Baikal rift. Strong deep earthquakes $(H \geq 600 \mathrm{~km})$ occurred only in South Kamchatka region within this period. They were accompanied by multiple aftershocks at the depths of 400-700km (Fig. 3). The strongest one is the earthquake in the Sea of Okhotsk which occurred at the depth of about $630 \mathrm{~km}$ with the magnitude of $M w=8.3$ (Global GMT). According to the data of the regional catalogue of Kamchatka Branch of Geophysical Service, the energy class of the earthquake is $K s=17$ (data.emsd.iks.ru/dbquaketxt_min). Its epicenter was located at the distance of about 100 $\mathrm{km}$ to the West from South Kamchatka coastline. The earthquake was felt at the distances up to 9500 $\mathrm{km}[9]$.

A histogram of earthquakes with $K>9$ gives the notion on the dynamics of seismicity at the depths of 400-700 km. It is clear from it that increase of seismicity begins in 2001 (Fig. 4). Almost from the same time, the disagreement of secular variations of the vertical geomagnetic field is observed at Paratunka and Patrony, Kakioka, Mamambetsu observatories. As we mentioned before, this disagreement is determined by the fact that the variation in 2001-2014 at Paratunka observatory almost did not manifest in the secular variation.

It is very difficult to discuss the possible nature of the anomalous behavior of the secular variation at Paratunka observatory as there is little information on the exact mechanism of conduction in the mantle. According to the data of seismic tomography, the zone of transition from the upper to the lower mantle in the South Kamchatka region differs by decreased velocity of seismic waves in comparison to the Japanese islands $[4,12]$. We can assume the following. In the result of the earthquakes at the depth of 400-700 km, energy released, temperature and pressure changed. It caused the increase of physical and chemical processes in rocks in the zone of transition from the upper to lower mantle. The latest investigations in the area of mineral physics show the possibility of slab depth dehydration in the mantle transition zone and extraction of water-containing liquid [5].

According to $[7,8]$, the electrical resistivity of rocks at the depths of $400-700 \mathrm{~km}$ is $100-5 \mathrm{Ohm} \cdot \mathrm{m}$, respectively. It is assumed that the liquid phase has the electrical resistivity of hundreds and thousands of fractions $\mathrm{Ohm} \cdot \mathrm{m}$ [2]. Appearance of the liquid phase in the galvanically bound state even in the volume of hundreds of fractions of a percent causes strong increase of rock electrical conductivity $[1,13]$. Integrated conductivity of the rock strata at the depths of 400-700 km grows by several orders. Formation of such a conductive depth inhomogeneity in South Kamchatka region is likely to have strongly affected the secular variations of the geomagnetic field. We may suppose that secular variations of the geomagnetic 


\section{References}

[1] Van'yan L.L., Electromagnetic sounding (Nauchniy mir,Moscow,1997) 219

[2] Gordienko V.V. and Loginov I.M., Earth Physics 2, 35-42 (2011)

[3] Braginskiy S.I., Geomagnetism and Aeronomy 10, 221-233 (1970)

[4] Jao D., Pirayno F., Liu L.,Geology and Geophysics 51, 1188-1203 (2010)

[5] Otani E., Chjao D., Geology and Geophysics 50, 1385-1392 (2009)

[6] Parkinson U., Introduction into geomagnetism (Mir,Moscow,1986) 528

[7] Rotanova N.M., Pushkov A.N., Depth electric conductivity of the Earth (Nauka,Moscow,1982) 148

[8] Semenov V.Yu., Bulletin of AS USSR, Earth Physics 3, 60-67 (1989)

[9] Chebrova A.Yu. et al., Volcanology and Seismology 4, 3-22 (2015)

[10] Yanovskiy B.M., Earth magnetism (LGU Pub.,Leningrad,1978) 591

[11] Currie R.G., J.Geophys.Res. 73, 2779-2786 (1968)

[12] Huang J., Zhao D., I. Phys. Planet. Inter. 73, 1-15 (2006)

[13] Shankland T.I., Waff H.S., J.Geophys.Res. 82, 5409-5417 (1977) 


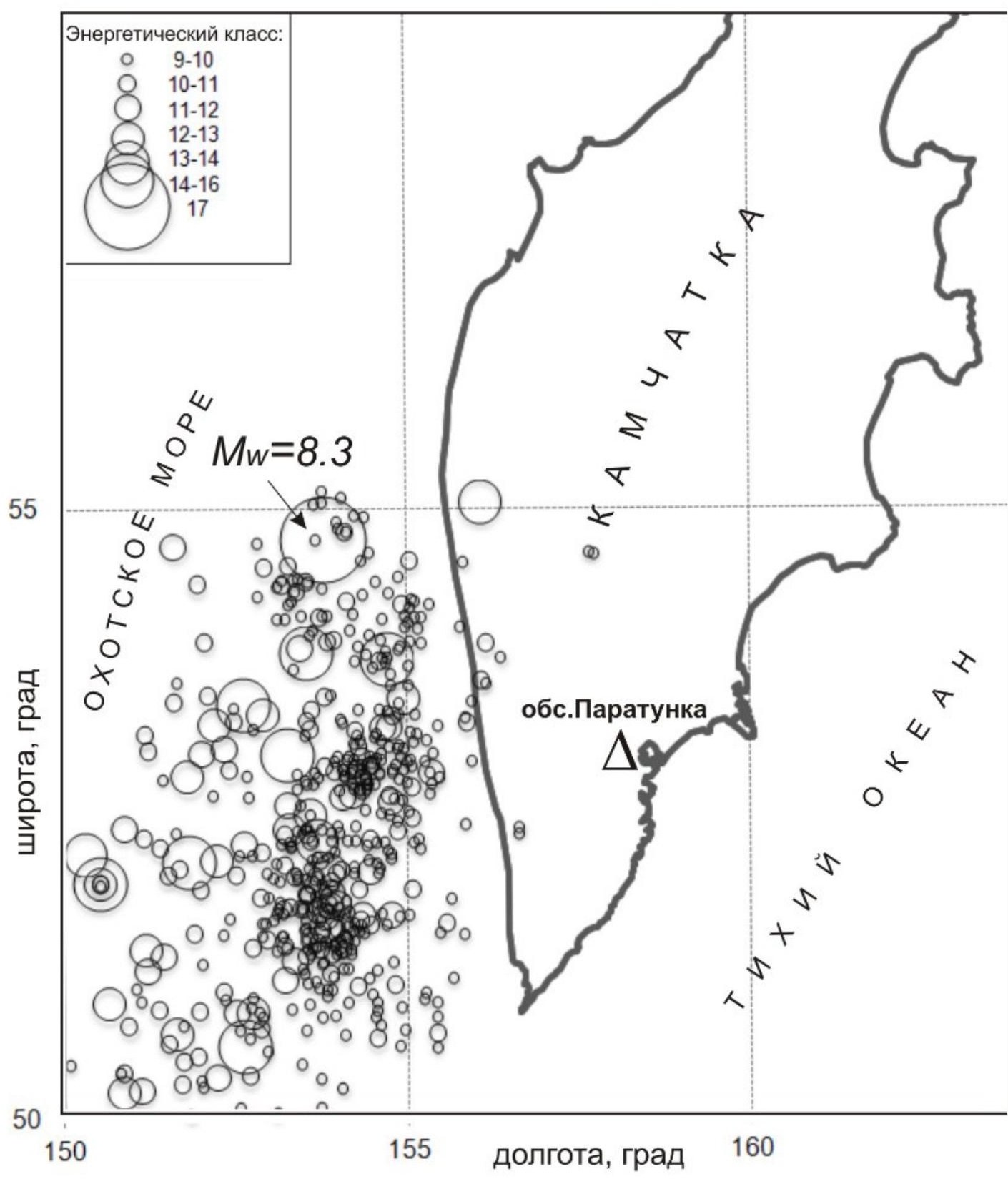

Figure 3. Scheme of location of deep earthquake epicenters $(400-700 \mathrm{~km})$ in South Kamchatka region from 1968 to 2015. Triangle shows the location of Paratunka geomagnetic observatory in Kamchatka. 


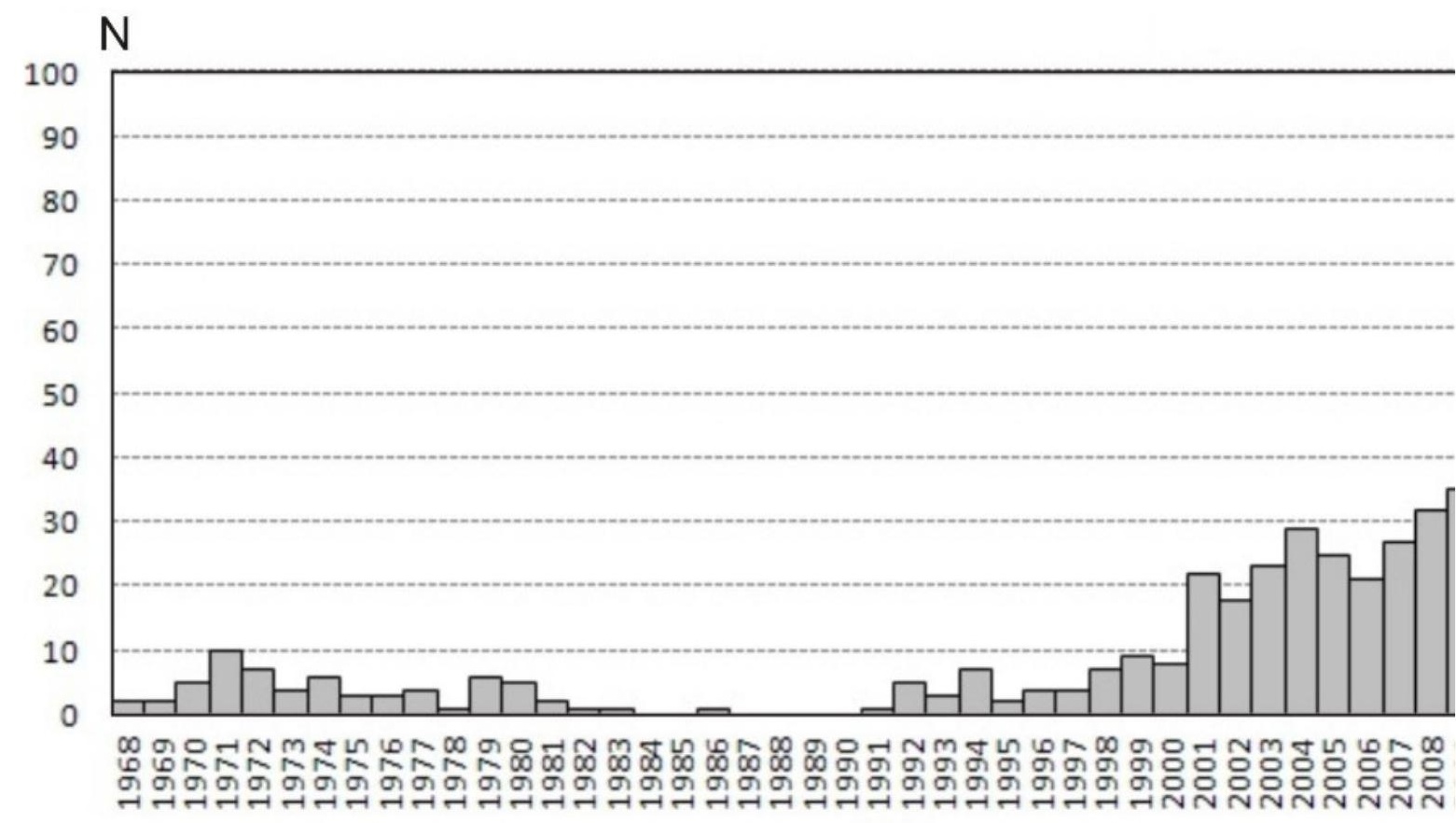

Figure 4. Histogram of deep (400-700 km) earthquakes with the energy class K=9-17 in South Kamchatka region (Fig.3) 